\title{
Evaluation of the Morphology of Accessory Canals of the Canalis Sinuosus via Cone-Beam Computed Tomography
}

Humeyra Tercanli Alkis

Akdeniz University

Gamze Cosan Ata

Akdeniz University

Ayse Tas ( $\nabla$ dt.ays.tas@gmail.com )

Istanbul Medipol University

\section{Research Article}

Keywords: Anatomy, canalis sinuosus, cone beam computed tomography, oral surgery

Posted Date: March 8th, 2022

DOI: https://doi.org/10.21203/rs.3.rs-1392555/v1

License: (c) (i) This work is licensed under a Creative Commons Attribution 4.0 International License.

Read Full License 


\section{Abstract \\ Purpose}

This study aims to assess the presence of accessory canal (AC) associated with canalis sinuous (CS), describing their frequency, lateralization, location, direction and measurements in cone beam computed tomography (CBCT).

\section{Methods}

Axial, coronal, sagittal, and cross-sectional reconstructions were analyzed in 248 CBCT images and the presence of CS, the presence of $A C$ associated with CS, the lateralization, localization and direction course of AC associated with CS was evaluated. CS diameter, AC diameter, distance between nasal cavity floor and CS (M1), CS and the buccal cortical bone (M2) and CS and the alveolar ridge (M3) was measured.

\section{Results}

CS dedected in all CBCT scans as bilaterally. The prevalence of AC associated with CS was $35.5 \%$. There was a significant difference between dental status and presence of AC associated with CS. There was a significant difference between gender, dental status, and lateralization of AC associated with CS. While M1 was greater in male patients than females, M3 was greater in female patients. M2 and M3 was greater in younger patients.

\section{Conclusion}

Clinicians performing surgical procedures should keep in mind that anatomical variations of the vascular nerve bundle may be seen. M1, M2, and M3 measurements can be affected by gender, age, and dental status.

\section{Introduction}

While the anterior maxilla is considered a safe area for surgical procedures, surgeons must pay close attention to the presence of neurovascular structures during operations [1]. Several surgical procedures (such as cyst or tumor operations, removal of supernumerary or impacted canine teeth, orthognathic, periodontal or endodontic surgery, and implant placement) can be conducted in the anterior maxilla [25]. Although the most striking anatomical formation in this region is the nasopalatine canal, insufficient evaluation of the canalis sinuous (CS), which is a variation of the anterior superior alveolar nerve, is one of the reasons for failure in surgical procedures [6]. 
CS was first described by Jones as an intraosseous canal with a diameter of approximately $2 \mathrm{~mm}$, running laterally to the nasal cavity, through which nerves and blood vessels departing from the infraorbital nerve pass through the posterior part of the infraorbital foramen. In the following years, the CS was defined as an anatomical structure in which neurovascular bundles such as the alveolar superior anterior nerve and artery are locate [7]. The branches of the CS ending at the floor of the nasal cavity and reaching the level of the maxillary anterior teeth are defined as variations of this structure [3].

Conventional periapical radiographs and orthopantomography are usually used in routine dental procedures; however, these devices are not sufficient to diagnose accessory channels due to low image quality, magnifications, distortions, and superimpositions [8]. Failure to identify CS with conventional imaging methods increases the risk of complications in surgical interventions for the maxillary anterior region. Paraesthesia and bleeding complications have been reported in patients in CS-related implant applications in the literature. In addition, case reports mimicking periapical lesion and root resorption in maxillary anterior teeth are presented. Therefore, it is important that CS can be identified radiographically [9]. Cone-beam computed tomography (СВCT) makes it easier to diagnose these anatomical structures due to the high resolution, cross-sectional view advantages [10].

This study aims to assess the presence of accessory canal (AC) associated with CS, describing their frequency, lateralization, location, direction, and measurements in CBCT scans.

\section{Material And Methods}

This retrospective study was approved by the Ethics Committee of the Medical School of ...... University and the study were carried out by the ethical rules of the Declaration of Helsinki (The ethics approval number was KAEK-473). Written consent was signed by all individuals before taking the CBCT.

\section{Data Collection}

The study material was selected from the archives of the University, Faculty of Dentistry, Department of Oral and Maxillofacial Radiology. CBCT records of patients, who presented between February 2020 and January 2021 for different reasons, were assessed and 516 CBCT images of patients over 18 years of age, in which CS entered the imaging field, were reached. The following exclusion criteria were used determine to the sample size and total of 248 CBCT images included in the study: (1) CBCT images of the patients with congenital disorders, (2) CBCT images suggesting trauma, (3) CBCT images suggesting surgical history except for central incisors extraction, (4) CBCT images with pathological disorders (such as cyst or tumor), (5) CBCT images with impacted canine or supernumerary teeth in the anterior maxilla and (6) CBCT images with technical artifacts.

CBCT images were divided into two groups based on age ( $<49$ years and $\geq 49$ years) and dental status in the anterior maxilla (group 1: both maxillary central incisors present and group 2: one or two maxillary central incisor absent). 


\section{Images}

CBCT images were obtained with the Vera view X800 CBCT device (J. Morita Mfg. Corp, Kyoto, Japan) by the same X-ray technician by the manufacturer's instructions $(320 \mu \mathrm{m} ; 4.8 \mathrm{~mA} ; 99 \mathrm{kvP}$ and $17.9 \mathrm{sn}$ for $15 \mathrm{x}$ $15 x 51.2$ field of view and $320 \mu \mathrm{m} ; 4.8 \mathrm{~mA} ; 99 \mathrm{kvP}$ and $35.8 \mathrm{sn}$ for $15 \mathrm{x} 15 \mathrm{x} 13.9$ field of view). Scans were analyzed using i-Dixel (Version 2.3.6.1 J Morita Mfg. Corp, Kyoto, Japan) as a viewing software.

All the CBCT images were evaluated by the two investigators, who were dentomaxillofacial radiologists, using the same LED monitor, approximately $40-50 \mathrm{~cm}$ away from the monitor. To maximize image quality, the images were evaluated in a dim light room and appropriate tonal adjustments. To avoid fatigue, only ten CBCT images were evaluated per day by the investigators.

The investigators were calibrated by evaluating 20 CBCT images together, and the other images were evaluated separately by the investigators. CBCT images where observers were undecided or could not inter-observer agreement were evaluated by a third investigator (H.T.A) with eight years of experience in dental radiology and a final decision has been made.

\section{Evaluation of CS and AC associated with CS}

Axial, coronal, sagittal, and cross-sectional reconstructions were analyzed for every image. While slice thickness of CBCT images was $1 \mathrm{~mm}$ in axial, coronal, and sagittal planes, it was $0.5 \mathrm{~mm}$ in crosssectional reconstructions. Suspicious images less than $0.5 \mathrm{~mm}$ in diameter in the axial plane were not considered AC [11]. The presence of CS was identified according to previous studies [7,12-14] and AC lateralization associated with CS was classified as the right side, left side, and bilateral. AC localization associated with CS was evaluated according to Olivera Santos et al [13]. The direction course of AC associated with CS was evaluated according to Von Arx et al [4] as curved direction, vertical direction, and $Y$ shaped in the coronal plane. The diameter of CS was measured at the junction with the accessory canal in the sagittal section [5]. The diameter of the AC associated with CS was measured in the axial plane. Measurements of the AC associated with CS were made in cross-sectional reconstruction as follows: (1) distance between nasal cavity floor and CS (M1); (2) distance between the emergence of the CS and the buccal cortical bone edge (M2); and (3) distance between the emergence of the CS and the most prominent point of the crest of the alveolar ridge(Figure 1) [15].

\section{Statistical analysis}

Data were statistically analyzed using an SPSS software package (version 23.0, SPSS Chicago, USA). The normality assumption was evaluated using the Shapiro-Wilk method. The homogeneity of variance had been verified through Levene's test. For analysis of between two group differences, the independent samples t-test was applied for data with a normal distribution, and the Mann Whitney $U$ test was used for data not displaying a normal distribution. Pearson chi-square test was used to analyze the difference between categorical variables. Statistical significance was assumed at $p<0.05$. 


\section{Results}

The CBCT images of 109 (44\%) male and 139 (56\%) female patients were included in the study; the age range was between 18-78 years and the mean age was $43.31 \pm 14.84$ years. There were 145 (58.5\%) patients in $<49$ years and $103(41.5 \%)$ patients in $\geq 49$ years and no significant difference between gender and age $(p=.219)$.

There were 209 (84.3\%) patients in group 1, and 39 (15.7\%) patients in group 2 according to the dental status. There was no significant difference between gender and dental status $(p=.126)$, however; there was a significant difference between age and dental status $(p<.001)$. One or two maxillary central incisors absence was more common in patients with $\geq 49$ years $(n=35)$ than in patients with $<49$ years $(n=4)$.

CS dedected in all CBCT scans as bilaterally. The prevalence of AC associated with CS was $35.5 \%(n=$ 89). While this prevelance $52.8 \%(n=47)$ for $<49$ years and $47.2 \%(n=42)$ for $\geq 49$ years, it was $48.3 \%$ ( $n$ $=43)$ for male patients and $51.7 \%(n=46)$ for female patients. In addition this prevelance was $76.4 \%(n=$ 68) for group 1 and $23.6 \%(n=21)$ for group 2 . There was no significant difference between age, gender and presence of $A C$ associated with $C S(p=.176$ and $p=.3$; respectively). On the other hand, there was a significant difference between dental status and presence of AC associated with $C S(p=.018)$.

A total of 129 AC associated with CS, which were the right side in 26 patients, on the left side in 23 patients, and bilaterally in 40 patients, were detected. Table 1 shows the distribution of lateralization of AC associated with CS according to age, gender, and dental status. While there was no significant difference between age and lateralization of AC associated with CS $(p=.89)$, there was a significant difference between gender, dental status, and lateralization of AC associated with CS ( $p=.022$ and $p$ $=.036$, respectively).

Table 1

Distrubition of lateralization of accesory canal associated with canalis sinuosus according to age, gender and dental status

\begin{tabular}{|lllll|}
\hline & & right side $(\mathrm{n})$ & left side $(\mathrm{n})$ & bilateral $(\mathrm{n})$ \\
\hline age & $<$ 49 years & 15 & 12 & 42 \\
\hline gender & $\mathbf{4 9}$ years & 11 & 11 & 38 \\
& male & 7 & 13 & 46 \\
& female & 19 & 10 & 34 \\
\hline dental status & group 1 & 22 & 20 & 28 \\
\hline $\begin{array}{l}\text { n: number of accessory canal associated with canalis sinuosus; group 1: both maxillary central } \\
\text { incisors present; group 2: one or two maxillary central incisor absent }\end{array}$ \\
\hline
\end{tabular}


AC associated with CS was the most often located in the central incisors region ( $n=48,37.2 \%)$ and this followed by canin region $(n=25,19.4 \%)$, lateral incisor region $(n=24,18.6 \%)$, between central and lateral incisors $(n=17,13.2 \%)$ and lateral of incisive foramen $(n=11,8.5 \%)$. AC associated with CS was the least often located in the first premolar region and posterior of the incisive foramen ( $n=2,1.6 \%$ for both). $\mathrm{AC}$ associated with CS did not determine in the anterior incisive foramen. Table 2 shows the distribution of localization of AC associated with CS according to age, gender, and dental status. There was no significant difference between age, gender, and dental status and localization of AC associated with CS $(p=.384, p=.63$ and $p=.367$, respectively).

Table 2

Distrubition of localization of accesory canal associated with canalis sinuosus according to age, gender and dental status

\begin{tabular}{|lllllll|}
\hline & age & & gender & & \multicolumn{2}{c|}{ dental status } \\
\hline & $<49$ years & $\mathbf{2 4 9}$ years & male & female & group 1 & group 2 \\
\hline central incisors $(\mathbf{n})$ & 23 & 25 & 21 & 27 & 30 & 18 \\
\hline central- lateral $(\mathbf{n})$ & 10 & 7 & 12 & 5 & 15 & 2 \\
\hline lateral incisor (n) & 16 & 8 & 16 & 8 & 18 & 6 \\
\hline canin (n) & 15 & 10 & 10 & 15 & 20 & 5 \\
\hline first premolar (n) & 0 & 2 & 0 & 2 & 1 & 1 \\
\hline lateral of IF (n) & 4 & 7 & 5 & 6 & 8 & 3 \\
\hline posterior of IF (n) & 1 & 1 & 2 & 0 & 2 & 0 \\
\hline $\begin{array}{l}\text { n: number of accessory canal associated with canalis sinuosus; IF: incisive foramen; group 1: both } \\
\text { maxillary central incisors present; group 2: one or two maxillary central incisor absent }\end{array}$ \\
\hline
\end{tabular}

While 93 (72.1\%) of the direction course of AC associated with CS presented curved direction, 33 (25.6\%) was vertical and only $3(2.3 \%)$ was $Y$ shape. Table 3 shows the distribution of direction course of AC associated with CS according to age, gender, and dental status. There was no statistically significant difference between the direction course of AC associated with CS and age, gender, dental status $(p=.762$, $p=.564$ and $p=.674$, respectively). 
Table 3

Distrubition of direction course of accesory canal associated with canalis sinuosus according to age, gender and dental status

\begin{tabular}{|lllll|}
\hline & & curved $(\mathbf{n})$ & vertical $(\mathbf{n})$ & Y shaped $(\mathbf{n})$ \\
\hline age & $<$ 49 years & 51 & 16 & 2 \\
\hline & $\geq$ 49 years & 42 & 17 & 1 \\
\hline gender & male & 50 & 15 & 1 \\
\hline & female & 43 & 18 & 2 \\
\hline dental status & group 1 & 67 & 24 & 0 \\
\hline $\begin{array}{l}\text { n: number of accessory canal associated with canalis sinuosus; group 1: both maxillary central } \\
\text { incisors present; group 2: one or two maxillary central incisor absent }\end{array}$ & \\
\hline
\end{tabular}

CS diameter did not show difference according to age, gender, dental status and presence of AC associated with CS ( $p=.854, p=.322, p=.273$ and $p=.290$, respectively). Table 4 shows the mean, standard deviation, minimum, maximum of the CS diameter according to age, gender, dental status, and presence of $A C$ associated with CS.

Table 4

The mean, standard deviation, minimum, maximum of the canalis sinousus diameter according to age, gender, dental status and presence of accesory canal associated with canalis sinousus

\begin{tabular}{|llllllll|}
\hline & & mean & SD & min & max & p values \\
\hline age & $<49$ years & 1.57 & 0.52 & 0.5 & 3.27 & .854 \\
\hline gender & male & 1.61 & 0.56 & 0.59 & 3.77 & .322 \\
\hline dental status & female & 1.59 & 0.55 & 0.5 & 3.63 & \\
\hline & group 1 & 1.59 & 0.55 & 0.5 & 3.63 & .273 \\
\hline AC associated with CS & group 2 & 1.54 & 0.58 & 0.59 & 3.77 & \\
\hline & presence & 1.62 & 0.6 & 0.5 & 3.77 & .290 \\
\hline $\begin{array}{l}\text { AC: accesory canal; CS: canalis sinousus; SD: standard deviation; group 1: both maxillary central } \\
\text { incisors present; group 2: one or two maxillary central incisor absent }\end{array}$ & & & & \\
\hline
\end{tabular}


AC diameter associated with CS was found between $0.5 \mathrm{~mm}$ and $2.53 \mathrm{~mm}$ and the mean diameter was $0.98 \pm .035 \mathrm{~mm}$. While the frequency of AC diameter associated with CS was $39.5 \%$ when AC diameter was at least $1 \mathrm{~mm}$, the frequency of AC diameter associated with CS was $60.5 \%$ when AC diameter was lower than $1 \mathrm{~mm}$. Table 5 shows the mean values of AC associated with CS diameter, M1, M2, M3 according to age, gender, and dental status. M1 was greater in male patients than females and this difference was significant $(p=.039)$. M2 and M3 was greater in $<49$ years than $\geq 49$ years and in group 1 than group 2 (for $M 2 p=.02$ and $p=<.001$, respectively and for $M 3 p=.004$ and $p=<.001$, respectively). In addition, M3 was greater in female patients than males $(p=.012)$.

Table 5

Mean values of all measurements according to age, gender and dental status

\begin{tabular}{|c|c|c|c|c|c|}
\hline & & AC associated with CS diameter & M1 & M2 & M3 \\
\hline \multirow[t]{3}{*}{ age } & $<49$ years & 0.96 & 13.32 & 7.03 & 9.28 \\
\hline & $\geq 49$ years & 1 & 13.41 & 6.21 & 7.06 \\
\hline & p & .625 & .912 & $02 *$ & $004^{*}$ \\
\hline \multirow[t]{3}{*}{ gender } & male & 0.95 & 14.14 & 6.45 & 7.39 \\
\hline & female & 1 & 12.55 & 6.86 & 9.13 \\
\hline & $\mathrm{p}$ & .275 & $.039 *$ & .246 & $.012^{\star}$ \\
\hline \multirow[t]{3}{*}{ dental status } & group 1 & 0.96 & 13.02 & 7.2 & 9.42 \\
\hline & group 2 & 1.02 & 14.28 & 5.17 & 5.07 \\
\hline & p & .658 & .192 & $<.001^{\star}$ & $<.001^{*}$ \\
\hline \multicolumn{6}{|c|}{$\begin{array}{l}\text { group 1: both maxillary central incisors present; group 2: one or two maxillary central incisor absent; } \\
\text { AC: accesory canal; CS: canalis sinousus; M1: distance between nasal cavity floor and canalis } \\
\text { sinousus; M2: distance between canalis sinousus and the buccal cortical bone edge; M3: distance } \\
\text { between canalis sinousus and the most prominent point of the crest of the alveolar ridge; } *:<.05\end{array}$} \\
\hline
\end{tabular}

\section{Discussion}

To prevent complications that may occur after surgical procedures in the maxilla anterior region, it is necessary to define the neurovascular structures in the region [16]. Contact with neurovascular bundles can cause sensory dysfunction, bleeding, or non-implant integration during surgical procedures $[9,17,18]$. It is important to determine the presence of neurovascular bundles of the infraorbital canal and the possibility of ACs must be detected before the surgical procedures. CS is one of these neurovascular bundles and is confused with an apical pathology on the upper canine [5].

Anatomical structures cannot be visualized on conventional radiographs due to superpositions. For this reason, $\mathrm{CBCT}$ has gained importance for three-dimensional imaging of the region before surgical procedures $[19,20]$. In addition, CBCT provides more details and uses lower doses of radiation compared 
with computed tomography, permits linear and angular measurements, and allows for multiplanar reconstruction of images [15]. Because of these advantages, CBCT was used to evaluate CS in the current study. The slice thickness of CBCT scans can be affected the detection of the anatomical or other structures and can be reduced artifacts [21]. The current study' slice thickness was $1 \mathrm{~mm}$ such as Anatoly et al. [22] in axial, coronal, and sagittal planes.

The high incidence of CS in the literature (99.3\% for Anatoly et al [22], 87.5\% for Wanzeler et al [5], $100 \%$ for Ghandourah et al [11] and $100 \%$ for Gürler et al [1] suggests to the authors that this formation is an anatomical structure, not a variation of the superior alveolar nerve. The results of the current study also support this situation. CS was detected bilaterally in all CBCT scans. On the other hand, CS can be associated with $\mathrm{AC}$ in the anterior maxilla. $\mathrm{AC}$ associated with $\mathrm{CS}$ is a common variation, which is clear when the canal has an extension to the alveolar ridge region [23]. The prevalence of AC associated with CS was found as $35.5 \%$ in the current study. This result is lower than Ghandourah et al [11] (67.6\%), Aoki et al [24] (66.5\%), Orhan et al [25] (70.8\%), Machado et al [3] (51.7\%), and von Arx et al [4] (56.7\%) and it is similar to Shan et al [26] (36.9\%) and Tomrukçu et al [8] (34.66\%). In addition, Olivera-Santos et al [13] found that 14 of their samples had a direct extension with the CS. These differences in prevalence can be caused by the AC diameter considered in the axial plane, different voxel sizes, and different exclusion criteria. Some studies have only considered CS larger than $1 \mathrm{~cm}$ in diameter $[4,13,26]$. Since cases of severe hemorrhage associated with $\mathrm{AC}$ with a diameter of $<1 \mathrm{~mm}$ during dental implant placement have been reported in the literatüre $[27,28]$ in the current study, the limit of AC diameter was accepted as 0.5 $\mathrm{mm}$. In addition, voxel size was $320 \mu \mathrm{m}$ in the current study.

Some studies $[4,25]$ reported an increasing frequency with age, although no significant difference was found. In the current study, the frequency was found to be higher in the younger patient group ( $<49$ years). However, this was not significant and this result may have been coincidental. While Ghandourah et al [11] found a difference between the prevalence of $A C$ and age (in the adult group), no such difference was found in the present study, consistent with the literatüre $[3,4,24]$.

When gender was taken into consideration, AC associated with CS was common in males than females in literature. While this difference was significant in some studies $[3,8,24]$ others didn't $[1,4]$. The current study didn't reveal such a difference and on the contrary female patients had slightly more common AC associated with CS than males; however, this difference didn't significant. Anatoly et al [22] showed a statistically higher prevalence in females $(p<.001)$. In addition, there was a significant difference between dental status and the presence of AC associated with CS. AC associated with CS was more common in group 1 than group $2(p=.018)$. This situation can result from the small patient number in group 2 or atrophy of the AC may be considered with tooth loss and this condition may be a separate issue to be investigated.

According to Manhas Junior et al [15] AC associated with CS is more common on the left side. The current study showed the most common lateralization of $A C$ was bilateral $(n=40)$. While the current study showed a significant difference between lateralization of AC associated with CS and gender and 
dental status, there was no difference between lateralization of AC associated with CS and age. Among the referenced studies no other studies are investigating this difference.

AC associated with CS is more prevalent in the incisor and canine region near the palate $[1,4,11,15,25]$, however, it can have different locations $[5,13,22,26]$. AC associated with CS was the most often located in the region of the central incisors at the current study such as Aoki et al [24] and Von Arx et al [4]. On the other hand, Manches Junior et al [15] found the most often location as beside the incisive foramen. The most commonly seen direction course of $\mathrm{AC}$ associated with CS in literature was curved and this followed by vertical and $Y$ shaped $[4,8]$, similar to the current study. There was no significant difference between age, gender, dental status, and localization of AC and direction course of AC associated with CS at the current study.

There are no exact data that describe the mean diameter of CS. While CS diameter is lower than the incisive foramen diameter [20] this structure must not be ignored during surgical procedures [5]. CS diameter can be measured at the bifurcation and in its terminal portion. Wanzelet et al ${ }^{5}$ showed that the diameter of CS is similar in both these portions. Gurler et al and Shan et al $[1,26]$ found CS diameter higher in males than females ( $p=.001$ and $p<.001$, respectively). In the current study, CS diameter was measured at the bifurcation portion and did not show a difference according to age, gender, dental status, and presence of AC associated with CS.

The diameter of AC was reported between $1.1 \mathrm{~mm}$ and $1.31 \mathrm{~mm}$ in literatüre $[3,4,8,13,26,29]$. The mean diameter was slightly lower $(0.98 \pm .035 \mathrm{~mm})$ in the current study. While the current study showed that when AC diameter lower than $1 \mathrm{~mm}$ the frequency of AC diameter associated with CS was $60.5 \%$, Aoki et al [24] found this frequency as $96.6 \%$, and Machado et al [3] found as $80 \%$. The current study showed there was no significant difference between AC diameter associated with CS and gender, age, and dental status. While this result is similar to Aoki et al [24] in gender, it contradicts Shan et al [26] and Tomrukçu et al [8]. They found that males were found to be significantly higher AC diameter associated with CS than females. In addition, Aoki et al [24], Machado et al [3], Tomrukçu et al [8] didn't find a significant difference between AC diameter associated with CS and age, similar with the current study.

While M1 and M3 were affected by gender, M2 didn't affect the current study. Wanzeler et al [5] found to be greater in males than females the distance between CS' terminal portion and the region of the alveolar ridge. Oliveira Santos et al [13] concluded that males can have different bone density, size, or shape from females. Although M1 was greater in male patients than females $(p=.039)$, M3 was greater in female patients than males $(p=.012)$ in the current study. While these results are similar to Tomrukçu et al [8] in M3 $(p=.009)$ and M2 ( $=.541)$, they did not find a difference between M1 and gender $(p=.548)$.

The alveolar bone is exposed to morphological changes over time. When age is taken into consideration, M2 and M3 were greater in young patients in the current study $\left(p=<.001\right.$ for both). While Tomrukçu et al ${ }^{8}$ found a significant difference between M1 and M2 and age ( $p=.001$ and $(p=.000$, respectively), such a difference didn't find in M3 $(p=.842)$. The inconsistency of the results obtained in both studies suggests 
that studies on the measurements of the AC associated with CS are insufficient. In addition, the current study shows that missing teeth reduces M2 and M3 values (Table 5). This result is not surprising given that missing teeth can cause alveolar bone loss.

Clinicians performing surgical procedures should keep in mind that anatomical variations of the vascular nerve bundle may be seen. AC diameter associated with CS is one of these variations, and many clinicians are unaware of its presence and location. CS was detected in all CBCT scans as bilaterally and the prevalence of $A C$ associated with CS was $35.5 \%$ at the current study. In addition lateralization of AC associated with CS, M1, M2, and M3 measurements can be affected by gender, age, and dental status.

\section{Declarations}

\section{Funding}

None to declare.

\section{Competing interests}

None to declare.

\section{Ethical approval}

This study was performed in line with the principles of the Declaration of Helsinki. Approval was obtained from the Institutional Review Board of Akdeniz University, according to protocol number 70904504/453.

\section{Patient consent}

There were no patients in the study.

\section{References}

1. Gurler G, Delilbasi C, Ogut EE, Aydin K, Sakul U (2017) Evaluation of the morphology of the canalis sinuosus using cone-beam computed tomography in patients with maxillary impacted canines. Imaging Sci Dent. 47.2:69-74.

2. Price JB, Thaw KL, Tyndall DA, Ludlow JB, Padilla RJ. (2012) Incidental findings from cone beam computed tomography of the maxillofacial region: a descriptive retrospective study. Clin Oral Implants Res. 23.11:1261-8.

3. Machado VC, Chrcanovic BR, Felippe MB, Manhaes Junior LR, de Carvalho PS. (2016) Assessment of accessory canals of the canalis sinuosus: a study of 1000 cone beam computed tomography examinations. Int J Oral Maxillofac Surg. 45.12:1586-91.

4. von Arx T, Lozanoff S, Sendi P, Bornstein MM. (2013) Assessment of bone channels other than the nasopalatine canal in the anterior maxilla using limited cone beam computed tomography. Surg Radiol Anat. 35.9:783-90. 
5. Wanzeler AM, Marinho CG, Alves Junior SM, Manzi FR, Tuji FM. (2015) Anatomical study of the canalis sinuosus in 100 cone beam computed tomography examinations. Oral Maxillofac Surg. 19.1:49-53.

6. Hu KS, Kwak HH, Song WC, Kang HJ, Kim HC, Fontaine C, et al. Branching patterns of the infraorbital nerve and topography within the infraorbital space. J Craniofac Surg. 2006;17(6):1111-5.

7. Jones FW. (1939) The anterior superior alveolar nerve and vessels. J Anat. 73(Pt 4):583-91.

8. Tomrukçu DN, Köse TE. (2020) Assesment of accessory branches of canalis sinuosus on CBCT images. Med Oral Patol Oral Cir Bucal. 25.1:e124-e30.

9. McCrea SJJ. (2017) Aberrations Causing Neurovascular Damage in the Anterior Maxilla during Dental Implant Placement. Case Reports in Dentistry. 2017:1-10.

10. Allareddy V, Vincent SD, Hellstein JW, Qian F, Smoker WR, Ruprecht A. (2012) Incidental findings on cone beam computed tomography images. Int J Dent. 2012. 871532.

11. Ghandourah AO, Rashad A, Heiland M, Hamzi BM, Friedrich RE. (2017) Cone-beam tomographic analysis of canalis sinuosus accessory intraosseous canals in the maxilla. Ger Med Sci. 15:Doc20.

12. Shelley AM, Rushton VE, Horner K. (1999) Canalis sinuosus mimicking a periapical inflammatory lesion. British Dental Journal. 186.8:378-9.

13. de Oliveira-Santos C, Rubira-Bullen IR, Monteiro SA, León JE, Jacobs R. (2013) Neurovascular anatomical variations in the anterior palate observed on CBCT images. Clin Oral Implants Res. 24.9:1044-8.

14. Neves FS, Oliveira LK, Ramos Mariz AC, Crusoé-Rebello I, de Oliveira-Santos C. Rare (2013) anatomical variation related to the nasopalatine canal. Surg Radiol Anat. 35.9:853-5.

15. Manhães Júnior LR, Villaça-Carvalho MF, Moraes ME, Lopes SL, Silva MB, Junqueira JL. (2016) Location and classification of Canalis sinuosus for cone beam computed tomography: avoiding misdiagnosis. Braz Oral Res. 30.1:e49.

16. Rodella LF, Buffoli B, Labanca M, Rezzani R. (2012) A review of the mandibular and maxillary nerve supplies and their clinical relevance. Arch Oral Biol. 57.4:323-34.

17. Jacobs R, Lambrichts I, Liang X, Martens W, Mraiwa N, Adriaensens P, et al. (2007) Neurovascularization of the anterior jaw bones revisited using high-resolution magnetic resonance imaging. Oral Surg Oral Med Oral Pathol Oral Radiol Endod. 103.5:683-93.

18. Jacobs R, Quirynen M, Bornstein MM. (2014) Neurovascular disturbances after implant surgery. Periodontology 2000. 66.1:188-202.

19. Liang X, Jacobs R, Lambrichts I. (2006) An assessment on spiral CT scan of the superior and inferior genial spinal foramina and canals. Surg Radiol Anat. 28.1:98-104.

20. Mraiwa N, Jacobs R, Van Cleynenbreugel J, Sanderink G, Schutyser F, Suetens P, et al. (2004) The nasopalatine canal revisited using 2D and 3D CT imaging. Dentomaxillofac Radiol. 33.6:396-402.

21. Jasa GR, Shimizu M, Okamura K, Tokumori K, Takeshita Y, Weerawanich W, et al. (2017) Effects of exposure parameters and slice thickness on detecting clear and unclear mandibular canals using 
cone beam CT. Dentomaxillofacial Radiology. 46.4:20160315.

22. Anatoly A, Sedov Y, Gvozdikova E, Mordanov O, Kruchinina L, Avanesov K, et al. (2019) Radiological and Morphometric Features of Canalis Sinuosus in Russian Population: Cone-Beam Computed Tomography Study. International Journal of Dentistry. 2019:2453469.

23. Ferlin R, Pagin BSC, Yaedú RYF. (2019) Canalis sinuosus: a systematic review of the literature. Oral Surg Oral Med Oral Pathol Oral Radiol. 127(6):545-51.

24. Aoki R, Massuda M, Zenni LTV, Fernandes KS. (2020) Canalis sinuosus: anatomical variation or structure? Surgical and Radiologic Anatomy. 42.1:69-74.

25. Orhan K, Gorurgoz C, Akyol M, Ozarslanturk S, Avsever H. (2018) An anatomical variant: evaluation of accessory canals of the canalis sinuosus using cone beam computed tomography. Folia Morphol (Warsz). 77.3:551-7.

26. Shan T, Qu Y, Huang X, Gu L. (2021) Cone beam computed tomography analysis of accessory canals of the canalis sinuosus: A prevalent but often overlooked anatomical variation in the anterior maxilla. J Prosthet Dent. 126.4:560-8.

27. Kalpidis CDR, Setayesh RM. (2004) Hemorrhaging Associated With Endosseous Implant Placement in the Anterior Mandible: A Review of the Literature. Journal of Periodontology. 75.5:631-45.

28. Hong YH, Mun SK. (2011) A case of massive maxillary sinus bleeding after dental implant. International Journal of Oral and Maxillofacial Surgery. 40.7:758-60.

29. Temmerman A, Hertelé S, Teughels W, Dekeyser C, Jacobs R, Quirynen M. (2011) Are panoramic images reliable in planning sinus augmentation procedures? Clin Oral Implants Res. 22.2:189-94.

\section{Figures}

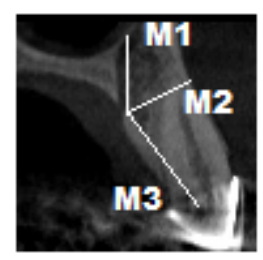

\section{Figure 1}

Measurements of the accesory canal associated with canalis sinousus 